University of Nebraska - Lincoln

DigitalCommons@University of Nebraska - Lincoln

Sociology Department, Faculty Publications

Sociology, Department of

2012

\title{
The Small-school Friendship Dynamics of Adolescent Depressive Symptoms
}

Jacob E. Cheadle

University of Nebraska-Lincoln, jcheadle2@unl.edu

Bridget J. Goosby

University of Nebraska-Lincoln, bgoosby2@unl.edu

Follow this and additional works at: https://digitalcommons.unl.edu/sociologyfacpub

Part of the Sociology Commons

Cheadle, Jacob E. and Goosby, Bridget J., "The Small-school Friendship Dynamics of Adolescent Depressive Symptoms" (2012). Sociology Department, Faculty Publications. 178.

https://digitalcommons.unl.edu/sociologyfacpub/178

This Article is brought to you for free and open access by the Sociology, Department of at DigitalCommons@University of Nebraska - Lincoln. It has been accepted for inclusion in Sociology Department, Faculty Publications by an authorized administrator of DigitalCommons@University of Nebraska - Lincoln. 


\title{
The Small-school Friendship Dynamics of Adolescent Depressive Symptoms
}

\author{
Jacob E. Cheadle and Bridget J. Goosby \\ University of Nebraska-Lincoln, Lincoln, NE, USA \\ Corresponding author - Jacob E. Cheadle, University of Nebraska-Lincoln, \\ 737 Oldfather Hall, Lincoln, NE 68588-0324, USA Email: j.e.cheadle@gmail.com
}

\begin{abstract}
Adolescence is a time when depressive symptoms and friendships both intensify. The authors ask whether friendships change in response to depressive symptoms, whether individual distress is influenced by friends' distress, and whether these processes vary by gender. To answer these questions, the authors use longitudinal Simulation Investigation for Empirical Network Analysis models to study how changes in friendships and depressive symptoms intertwine with each other among all adolescents as well as boy-only and girl-only networks in seven smaller K-12 Add Health schools. The findings indicate that distressed youth are more likely to be socially excluded, though depressive symptoms are also a basis for friendship formation. Moreover, friends influence one another's mood levels. These processes differ for boys and girls, however, such that distressed girls are more likely to face exclusion and distressed boys are more likely to befriend and subsequently influence one another.
\end{abstract}

Keywords: adolescents, depressive symptoms, gender, networks

Adolescence is an emotionally tumultuous time when depressive symptoms increase (Wade, Cairney, and Pevalin 2002) and risks for suicide ideation and psychological disorders intensify (Pine et al. 1999; Wilson and Deane 2010). Approximately 35 percent of adolescents experience depressive symptoms (Compas, Ey, and Grant 1993), and depression rates are two or three times higher for girls than boys (Nolen-Hoeksema and Girgus 1994). Adolescence is also a very social period when interpersonal connections to peers and friends become central to young peoples' lives (Crosnoe 2011). Given the coemergence of emotional distress and increased socializing over this early period of the life course, we ask whether peer interactions amplify or mollify distress. Studies of adolescent mental health have focused on family fac- tors for years (e.g., Avison and McAlpine 1992), but less attention is given both to how emotional distress is embedded in friendships and how those mechanisms are gendered (Rubin, Bukowski, and Parker 2006).

We focus here on a number of pathways through which distress can become socially intertwined into the interpersonal lives of adolescents. For example, distressed adolescents may withdraw from their peers, or their peers may view them more negatively and withdraw from them, with the result that they have fewer friends (Rose, Carlson, and Waller 2007; Schaefer, Kornienko, and Fox 2011). Additionally, distress may diffuse among friends, or it may draw adolescents to one another and lead to friendships (e.g., Kandel 1978; Weerman 2011). Consequently, the role of emotional distress in 
adolescents' social lives is likely to be multifaceted to the extent it reflects the consequences of friendships, as well as being a basis for them. In addition, we give special attention to gender-specific friendship dynamics because societal norms and socialization efforts by parents, other adults (Rhodes and Lowe 2009; West and Zimmerman 1987), and educational institutions (Eder and Parker 1987) lead to gendered youth cultures and different emphases in adolescent friendships (Hall 2011).

To address these issues, we interlink individual changes in depressive symptoms to the longitudinal friendship networks in seven small $(n<300)$ National Longitudinal Study of Adolescent Health (Add Health) high schools. Our focus on these small schools reflects the circumscribed nature of the social networks in these settings. Size places constraints on knowledge about other peers, and this structural constraint increases quickly with school size to the point at which most students do not know one another and have little knowledge about one another's affective states and tendencies.

In addition, prior studies suggest that emotional distress processes differ among boys and girls (Rudolph 2002), so we assess the social dynamics of distress among all adolescents within schools and among boys and girls separately. We therefore evaluate multiple mechanisms connecting depressive symptoms and social relations to each other during adolescence using new longitudinal social network models (Snijders, Steglich, and Schweinberger's [2007] Simulation Investigation for Empirical Network Analysis [SIENA] model). This approach allows us to study both friend selection and influence mechanisms directly while accounting for structural network and other background factors.

\section{Literature Review}

Although much attention has been given to the social dynamics of externalizing behaviors (e.g., Mercken et al. 2010; Pearson, Steglich, and Snijders 2006), there is a growing, albeit relatively small, social network-based sociological literature studying adolescent psychological outcomes. Recently, Falci and McNeely (2009) reported that Add Health adolescents with either very small or very large personal networks have more depressive symptoms. Gender differences indicated ill effects of overintegration at low levels of network cohesion for girls, with consequences of overintegration occurring at high levels of network cohesion for boys. Their study builds on Ueno's (2005) and Hansell's (1985) earlier examinations of social integration, which together showed that linear operationalizations of integration have only modest negative associations with distress.

We focus here on two limitations of this prior work. First, the network measures used (i.e., Falci and McNeely 2009; Ueno 2005) did not reflect the actual depressive symptoms of friends and consequently did not shed light on friend influence processes. Psychologists, however, argue that having distressed friends increases individual risk for distress (Hogue and Steinberg 1995; Stevens and Prinstein 2005). Second, the issue of friend selection has not been addressed directly in studies of social influence. Selectivity is a generally acknowledged challenge for peer influence studies because the outcomes researchers and others care about can be sources of friendship rather than merely consequences of them (Cohen 1977). Yet despite concerns that social selection processes bias peer effect estimates (e.g., Billy and Udry 1985), no studies of adolescent distress, or social integration, have directly incorporated friend selection into models estimating the mutual influences friends have on one another. However, our purpose is not merely to isolate social influence effects by controlling for selection, but also to begin studying the role of distress in friendship processes.

\section{Social Influence}

Social or friend influence refers to the process by which emotional distress diffuses among friends (Friedkin 1998; Umberson, Crosnoe, and Reczek 2010). Interactional views of depression describe negative mood induction as a social influence process that spreads depressed affect between friends (Coyne 1976a, 1976b; Prinstein 2007). For example, corumination, excessive reassurance seeking, and negative feedback seeking are sources of negative influence among friends (Dishion and Tipsord 2011; Rose 2002). These processes may diffuse emotional distress directly, because providing support can be costly (Kessler and McLeod 1984), or because individuals try to find emotional balance with their social relations (Heider 1958). Recent evidence showing that friends influence and perpetuate loneliness (Cacioppo, Fowler, and 
Cristakis 2009) and both positive and negative mood in one another (Fowler and Christakis 2008; Hogue and Steinberg 1995; Stevens and Prinstein 2005) support interactional models of affect diffusion. We thus hypothesize that adolescent depressive symptoms will change over time to become more similar among friends.

Evidence of sex differences in social influence is contradictory, however (Giordano 2003; Johnson 1991). Hogue and Steinberg (1995), for example, suggested that boys' distress is more susceptible to friend influences, while Stevens and Prinstein (2005) reported the opposite. To the extent that relationships among girls are more intensive and require more emotion work to provide empathy (Hochschild 1979), distress may more strongly diffuse among them as a cost of providing support, because corumination negatively affects mood and because support increases relationship stress (Dishion and Tipsord 2011; Kessler and McLeod 1984; Rudolph 2002). Alternatively, Hochschild's (1990) notion of forced emotional suppression suggests that influence may be greater among boys if girls are able to provide support accommodating the expression of negative feelings and moods, while boys are unable or unwilling to express themselves because they suppress and hide their distress for fear of social exclusion (Gallerani, Garber, and Martin 2010; Johnson 1991; Zeman and Shipman 1997). Thus, prior studies provide conflicting evidence for how gender moderates the baseline influence hypothesis. Variations in prior findings may also partly reflect the inability of these studies to adequately address friend selection processes, a topic we turn to next.

\section{Friend Selection}

Fine (1980) argued that friendships cannot form and be maintained without three factors: (1) structural constraints conducive to ongoing interactions, such as the social contexts provided by schools; (2) individual inclinations that allow friendships to form; and (3) the existence of satisfying interactions. For example, youth who share characteristics are more likely to become friends (Goodreau, Kitts, and Morris 2009; Shrum, Cheek, and Hunter 1988), and same-sex friendship groups are more common than mixed-sex groups in adolescence (Cairns, Xie, and Leung 1998; Shrum et al. 1988). The degree to which students form relationships with one another thus reflects a variety of social and interpersonal mechanisms drawing youth together and influencing the quality of their relationships. We focus here on three specific ways that emotional distress can influence friend selection: (1) homophilous selection, (2) social exclusion, and (3) social withdrawal (cf. Brown and Larson 2009).

Homophilous selection captures the idea that "birds of a feather flock together" (i.e., McPherson, Smith-Lovin, and Cook 2001), with the associated hypothesis that adolescents with similar depressive symptom levels are more likely to be friends (e.g., Billy, Rodgers and Udry 1984; Hallinan and Kubitschek 1990). Psychological predispositions (i.e., extraversion) play important roles in social network formation and structure (Kalish and Robins 2006), and this appears to be true for emotional distress among both adolescents (Hogue and Steinberg 1995) and adults (Merikangas 1984; Rosenblatt and Greenberg 1988; Wenzlaff and Prohaska 1989). Moreover, adolescents appear to select friends with similar substance use and aggression levels (e.g., Cairns et al. 1988). Thus, emotional distress may be a source of interpersonal bonding that connects youth to one another through corumination and other support processes (Dishion and Tipsord 2011).

The first of the other friendship selection processes, social exclusion, captures the idea that distressed individuals are pushed out to the periphery of the friend network and end up socially marginalized (Bendgren et al. 2002; Cacioppo et al. 2006; Coyne and Downey 1991; Link et al. 1989). This can happen because distressed youth express more aversive behavior and lower reciprocity, thereby requiring more maintenance effort and increasing the likelihood that they are socially excluded by others (Bendgren et al. 2002; Coyne 1976a, 1976b; Coyne and Bolger 1990; Youngren and Lewinsohn 1980). The other mechanism, social withdrawal, may also lead to social isolation or marginalization (Crosnoe, Frank, and Mueller 2008). Although healthier individuals have larger networks and are more likely to actively seek support from friends, depressed youth may withdraw socially to cope with depressive symptoms or because they perceive themselves to be socially excluded (Rose et al. 2007; Schaefer et al. 2011). These two mechanisms lead to the hypotheses that more distressed adolescents will be less popular and that more distressed adolescents will consider fewer peers 
to be their close friends. Determining the differential contributions between these and the homophilous selection mechanism is one of the central goals of this study.

The intersection of gender, emotional distress, and friend selection has not been an intensive study topic, making the focus here novel and exploratory. Instead, researchers have focused attention on relationship style, stress and coping processes, and emotional provisions in relationships, in attempts to understand influence processes (Rose and Rudolph 2006 provide a detailed review). In general, girls provide more support to one another but also expect more in return. They also express more self-disclosure, intimacy, and reciprocity in their relationships (Hall 2011). Evidence from network studies suggests that girls' networks are characterized by closer, more intimate ties, with a stronger focus on the dyad and interpersonal relationships, whereas boys' networks are typically more expansive and less focused on dyadic interactions (Benenson 1990; Benenson et al. 2011; Urberg et al. 1995).

How these factors intersect with depressive symptoms to influence friendship selection is not entirely clear, however. For example, if boys are more likely to be socially sanctioned because role expectations preclude expressions of emotional distress, then they will be more likely to be excluded from the network (Gallerani et al. 2010; Johnson 1991; Witvliet et al. 2010). At the same time, to the extent that distressed girls expect support, they may be perceived as "needy" and consequently be viewed as less desirable friends (Prinstein et al. 2005). With respect to withdrawal, the greater value placed on intimacy, self-disclosure, empathic understanding, and emotional support among girls may keep distressed girls socially connected (Hall 2011). In addition, because of these relationship differences between boys and girls (Hall 2011; Rudolph 2002), securing accepting and supportive friends may create a stronger basis for homophilous selection among boys. That is, because both depression and support are more common among girls, the overall impact on selection processes may be smaller for them. Alternatively, emphasis on disclosure may provide socially relevant information that allows girls to identify one another in the network, thus fostering homophilous selection. Thus, different perspectives suggest the possibility that whether and how distress affects friendship selection is gendered, though to our knowledge, this is the first study to directly estimate these processes using network models and actual measures of friendships rather than self-reports.

\section{Network and Background Factors}

In addition to the core selection and influence mechanisms, we also control for additional factors in both the selection and influence models that could introduce bias if not accounted for. For example, youth with elevated depressive symptoms are more likely to be female (Cyranowski et al. 2000), have less educated parents (Goodman, Slap, and Huang 2003), have single parents and less support (Carlson 2006), and lower self-esteem (Dumont and Provost 1999). There is also evidence of homophily among youth on the basis of gender, grade level, race, and socioeconomic status (Goodreau et al. 2009; Moody 2001). Because these factors are related both to friend selection and depressive symptoms, they are included in both the selection and influence models.

We also account for a number of network processes. Steglich, Snijders, and Pearson (2010) discussed the fact that network processes are themselves sources of influence and change that can produce what appear to be selection and influence effects and so must be controlled for in statistical network models. Along with reciprocity, network closure captures structural processes leading to friendship change (Snijders, van de Bunt, and Steglich 2010). For example, transitive closure captures the processes whereby a focal adolescent forms a new friendship with another friend's friend. In this way, networks "close," not because of depressive symptoms or other factors but because of the way that the structure of the friendship network creates opportunities for relationships. In addition, as the work of Falci and McNeely (2009) shows (see also Keiley et al. 2000), popularity or social integration can likewise be an important structural feature that protects youth from experiencing depressive symptoms. Accordingly, it is important to consider structural factors in both social selection and social influence models.

\section{Methods}

Data come from waves 1 and 2 of the inhome components of Add Health. Add Health 
is a cluster stratified longitudinal study of 7 th to 12th grade youth begun in 1994 with in-school questionnaires administered to approximately 90,000 students in 140 schools. A nationally representative sample of over 20,000 students was drawn from the in-school study, and data were collected in the home in 1995 and again approximately one year later at wave 2 . This longitudinal sample consists of a core probability sample and special oversamples (racial/ethnic, disabled, and genetic) including 16 "saturated" school settings where efforts were made to collect data on all attending 7 th to 12 th grade students so that a network sample could be maintained over time. Of these 16 schools, two were large (about 1,000 and 2,100 students), and 14 were much smaller ( $n<300$ students).

We used seven of the saturated settings, all K- 12 schools that are relatively racially and ethnically homogeneous, to construct the sample. The decision to use these schools was based on several criteria (this is also addressed further in the "Discussion" section). First, because our analysis requires longitudinal measures of friendship networks, we were limited to the saturated schools. Second, one of the schools was a special education school, and another six were 6 th to 8 th grade schools. We chose not to use the latter schools because the 8th graders moved into high schools for which full network data are not available. Third, larger schools capture different macro-settings than the small schools, as indicated by the enormous size differences, with the grade cohorts of the big schools being larger than the entire 7 th to 12 th grade cohorts of the smaller schools together. Accordingly, we focus on the social dynamics in a collection of smaller, more homogeneous settings. The joint sample size of the small schools constituting this study is 798 mostly white 7 th to 12 th grade students. The largest school contributed 163 students to the analysis, and the smallest contributed 61 . Three were public rural schools $(n=363)$, and the remaining four were private $(n=435)$, three of which were urban $(n=374)$. Network data were present for 70 percent to 89 percent of the students on the school-provided roster, and these rates have previously been shown to be acceptable for social network analysis (Huisman 2009; Kossinets 2006).

\section{Measures}

Dependent and focal independent variables. The first variable, the friendship network ma- trix, is used to analyze friend affiliation over two waves. These two matrices at waves 1 and 2 map the interconnections between individuals. The adolescent friendship networks at both waves are constructed from two sets of variables requesting nominations of up to five male and five female friends from the school roster. The total sample makes use of all available nominations, and the sex specificity in the questions allowed us to construct boy-only and girlonly networks separately for the sex-specific analyses. The psychological variable used for the analysis is based on 19 ordinal items from the Center for Epidemiologic Studies Depression Scale (CES-D; Radloff 1977). The scale is based on a series of questions inquiring how often during the past week the respondent felt depressed, enjoyed life, and so on, with response categories ranging from "never or rarely" $(0)$ to "most or all of the time" (3). Because the models require ordinal dependent actor variables, we recoded the CES-D scale into deciles. ${ }^{1}$ Cronbach's $\alpha$ was .85 at both waves.

Control variables. For controls, we include whether the respondent is female (coded 1), grade (range $=7$ to 12 ), whether the youth is white (coded 1), and whether the parent is single (coded 1). Parent education of the responding parent is included as a five-value variable with categories ranging from "did not graduate from high school" (1) to "received postgraduate training" (5). Scales for parent support and respondent self-esteem were created from wave 1 in-home items. The standardized parent support scale $(\alpha=.86)$ is based on an eight-item ordinal (range $=1$ to 5 ) "closeness to parents" scale (see Cornwell 2003). The standardized self-esteem scale $(\alpha=.81)$ is based on five ordinal items (range $=1$ to 5 ) inquiring whether adolescents feels as if they are doing everything just about right, have a lot of good qualities, have a lot to be proud of, like themselves just as they are, and whether they feel socially accepted.

Finally, we include the number of off-list nominations provided by the adolescent during the network portion of the survey. Although the majority of nominations in Add Health are to friends at school, close to 30 percent are not (Falci and McNeely 2009). In addition, we also include an indicator for whether the respondent was in the restricted nomination sample, because some adolescents were allowed to nominate only one male and female friend because of a survey implementation error. The result of 
this error is that the full friendship network was not captured at the wave 1 in-home survey for 40 percent of the youth in the sample. We carried the wave 1 in-school nominations forward for these youth ${ }^{2}$ (note that the present study relies on the subsequent wave 1 and 2 in-home surveys) to preserve the full network so that we could conduct the longitudinal social network analysis. There will thus be greater change in the networks for the restricted nomination than regular sample, so we have constructed this indicator to reflect the fact that overall change in friendships will be greater for these adolescents.

\section{The Model}

The analysis uses the new class of SIENA models developed by Snijders (1996, 2001) and colleagues (Snijders et al. 2007). The model has two components: a network model and a behavioral model that together constitute a system of interdependent equations. The models decompose the contributions of selection and influence (see Steglich et al. 2010) by conditioning on wave 1 and then modeling subsequent changes in friendships and CES-D score from that point. Coefficients are calculated using a method of moments estimator capturing aggregate changes in social networks and CESD score between observations. The parameter estimates are refined with an agent-based simulation model that is used to calculate their uncertainties and guides their interpretation. The simulation model decomposes changes in the network into a series of the smallest possible changes in either one tie or a one-decile change in CES-D score at a time for a randomly chosen adolescent. In this way, very complicated change patterns are modeled as the accumulation of many small changes across micro-steps in a way consistent with the total aggregate observed pattern of network and CES-D change.

The model constitutes a continuous time Markov process such that each actor's decision for whether or not to change one tie or behavior is determined by the current state of his or her network-behavioral configuration. A rate parameter governs how often actors have change opportunities so that only one actor can act at a time, and actors cannot coordinate with one another or optimize beyond their current state and the next state. The selection model is thus concerned with tie changes in the friendship network, $x$, where ties between ego ( $i$; rows) and alter $\left(j\right.$; columns) are denoted as $x_{i j}=1$, and the lack of a tie is $x_{i j}=0$. The network evaluation function, $f_{i}^{\text {net }}(x)$, for actor $i$ is defined as

$$
f_{i}^{\text {net }}(x, z, v)=\sum_{k} \beta_{k}^{\text {net }} s_{i k}^{\text {net }}(x, z, v)
$$

where $\beta_{k}^{\text {net }}$ are the parameters and $s_{i k}^{\text {net }}(x, z, v)$ are the effect parameterizations defined in Table 1 , which include CES-D score $(z)$ and additional control variables $(v)$. In each micro-step, the configuration with the most positive $f_{i}^{\text {net }}$ value plus a small amount of randomness determines how the network is modified. There is no change, a new friend is nominated, or an existing friendship is terminated. The model thus determines actor i's modification of his or her network by choosing his or her optimal tie configuration across all other actors $(j)$.

The specific parameters in Table 1 capture the ways that covariates are operationalized in this study to influence changes in ties. Positive values on these effects contribute to the evaluation function and thus express preferences for ties, while negative values indicate the opposite. The alter, ego, and similarity effects are the key selection mechanisms central to this process. The alter effect is the sum of the covariate values for each alter $(j)$ that ego $(i)$ is tied to and thus captures the influence of CES- $\mathrm{D}_{j}$ (or another $v_{j}$ ) on the likelihood of friendship. A negative parameter estimate is therefore an indicator of exclusion. The ego effect reflects the ego's covariate value on $z_{i}$ or $v_{i}$ and the count of his or her nominations. For CES-D score, this indicates the extent to which distress is related to the extensiveness of activity in the network, with withdrawal indicated by a negative value of $\beta_{k}^{\text {net }}$. Similarity is a dyadic effect expressing homophilous selection that is based on how similar ego $\left(z_{i}\right)$ and alter $\left(z_{j}\right)$ are to each other. This is captured as their absolute difference on $z$ or $v$ relative to the observed range of $z / v(0$ $=$ maximally dissimilar, $1=$ maximally similar). A positive value of $\beta_{k}^{\text {net }}$ thus indicates a preference for ties among those with similar CES-D or $v$ levels, as predicted by the homophilous selection hypothesis.

Additional parameters and textual descriptions are provided in Table 1, including structural parameters for reciprocity and network closure. Accounting for network closure processes is of substantial importance because they reflect alternative confounding mechanisms driving changes in friendships (Steglich et al. 
Table I. Description of the Main Model Parameters for the CES-D Change Model

\begin{tabular}{|c|c|c|}
\hline Parameter & Formula $=s_{k i}^{\text {net }}(x)$ & Description \\
\hline \multicolumn{3}{|c|}{ Selection parameters and covariate effects } \\
\hline Alter (potential friend) & $\sum_{j} x_{i j} v_{j}$ & $\begin{array}{l}\text { Main effect of potential friend's CES-D score or varname } \\
\text { on the selection of friends ( } \beta=\text { exclusion) }\end{array}$ \\
\hline Ego (adolescent) & $v_{i} \sum_{j} x_{i j}$ & $\begin{array}{l}\text { Main effect of adolescent's CES-D score or varname on } \\
\text { the selection of friends ( }-\beta=\text { withdrawal) }\end{array}$ \\
\hline $\begin{array}{l}\text { Similarity potential } \\
\text { friend and adolescent }^{\mathrm{a}}\end{array}$ & $\sum_{j} x_{i j}\left(\operatorname{sim}_{i j}-\overline{\operatorname{sim}}\right)$ & $\begin{array}{l}\text { Tendency to choose a friend based on CES-D score or } \\
\text { varname similarity ( }+\beta=\text { homophilous selection) }\end{array}$ \\
\hline $\begin{array}{l}\text { Same potential friend } \\
\text { and adolescent }{ }^{b}\end{array}$ & $\sum_{j} x_{i j} I\left(v_{i}=v_{j}\right)$ & $\begin{array}{l}\text { Tendency to choose friends with exactly the same } \\
\text { varname }\end{array}$ \\
\hline \multicolumn{3}{|l|}{ Structural network effects } \\
\hline Out-degree & $\sum_{j} x_{i j}$ & General tendency to choose a friend \\
\hline Reciprocity & $\sum_{i} x_{i j} x_{j i}$ & Tendency to have reciprocal friendships \\
\hline Transitive triplets & $\sum_{j, h} x_{i h} x_{i j} x_{j h}$ & Tendency to become the friend of a friend's friend \\
\hline Three-cycle ${ }^{c}$ & $\sum_{j, h} x_{i j} x_{j h} x_{h i}$ & $\begin{array}{l}\text { Tendency for a friend's friend to chose the focal ado- } \\
\text { lescent as a friend }\end{array}$ \\
\hline Number distance $=2^{\text {de }}$ & $\#\left(j \mid x_{i j}=0, G=2\right)$ & $\begin{array}{l}\text { Tendency to be indirectly connected through one } \\
\text { intermediary }\end{array}$ \\
\hline \multicolumn{3}{|l|}{ Rate parameters } \\
\hline Basic rate parameter & - & $\begin{array}{l}\text { Determines the average number of change opportuni- } \\
\text { ties in each period }\end{array}$ \\
\hline varname & - & Differences in the rate of change by varname \\
\hline
\end{tabular}

Note: All covariates are centered at the grand mean, and $v$ generically refers to Center for Epidemiologic Studies Depression Scale (CES-D) score and additional covariates (varname).

a. $\operatorname{sim}_{i j}=1-\left|v_{i}-v_{j}\right| / \max _{i j}$, and $\overline{\operatorname{sim}}$ is the average similarity.

b. $I\left(v_{i}=v_{j}\right)$ is a function indicating whether $v_{i}=v_{j}(=I)$ or $v_{i} \neq v_{j}(=0)$.

c. A positive effect implies generalized reciprocity, while a negative effect with a positive transitive triplet effect suggests local hierarchies (Ripley et al. 20I I).

d. This effect is an inverse effect of network closure, so effects tend to be negative, suggesting that indirect connections tend to close through, for example, the formation of transitive triplets, or else the indirect connections are lost.

e. This function is the number (\#) of actors at geodesic distance $=2(G=2)$ to which the actor is not directly tied $\left(x_{i j}=0\right)$.

2010). For example, the friends of friends are more likely become friends with one another. Without controlling for this process, friendship changes could appear to arise from homophily on depressive symptoms when they actually reflect the opportunities afforded from socializing together because of shared friendships (transitive triplets). Closure is also captured with the distance $=2$ effect, which is expected to be negative as an indication that adolescents prefer to be directly rather than indirectly connected to one another. The three-cycles effect is a measure of whether local hierarchies form and is measured by the presence of $i \rightarrow j \rightarrow k \rightarrow$ $i$ ( $i$ nominated friend $j$, who nominated $k$, who nominated $i$ ) nomination patterns. A positive parameter reflects the tendency away from local hierarchy (i.e., generalized exchange), while a negative sign suggests differential popularity and thus local hierarchy among friends.

In the models we present, each randomly chosen actor's decision is actually composed of two parts: an actor can either change his or her network, $f_{i}$ net, or his or her CES-D value can adjust up or down by one unit. In the behavioral evaluation function

$$
f_{i}^{\text {beh }}(x, z, v)=\sum_{k} \beta_{k}^{\text {beh }} s_{i k}^{\text {beh }}(x, z, v)
$$

the statistics $s_{i k}^{\text {beh }}(x, z, v)$ predict changes in CES-D score as a function of current CES-D values $(z)$, the state of the network $(x)$, and other variables $(v)$, such that $+\beta_{k}^{\text {beh }}$ indicates increases and $-\beta_{k}^{\text {beh }}$ indicates decreases in CES-D level, much like an ordinal logit model. Average friend similarity is the focal parameter cap- 
Table 2. Description of the Main Model Parameters for the Network Selection Model

\begin{tabular}{|c|c|c|}
\hline Parameter & Formula $=s_{i k}^{\text {beh }}(x, z)$ & Description \\
\hline \multicolumn{3}{|l|}{ Focal influence parameter } \\
\hline Average friend similarity ${ }^{a}$ & $x_{i+}^{-1} \sum_{j} x_{i j}\left(\operatorname{sim}_{i j}-\overline{\operatorname{sim}}\right)$ & $\begin{array}{l}\text { Main effect of friends' average CES-D score } \\
\text { similarity on individual CES-D score } \\
(+\beta=\text { friend influence) }\end{array}$ \\
\hline varname $^{\mathrm{b}}$ & $z_{j} v_{i}$ & Main effect of varname on CES-D score \\
\hline \multicolumn{3}{|l|}{ Shape parameters } \\
\hline Linear shape parameter & $z_{i}$ & $\begin{array}{l}\text { The overall shape of the CES-D score } \\
\text { distribution modeled as a quadratic } \\
\text { function }\end{array}$ \\
\hline Quadratic shape parameter & $z_{i}^{2}$ & \\
\hline \multicolumn{3}{|l|}{ Rate parameters } \\
\hline Basic rate parameter & - & $\begin{array}{l}\text { Determines the average number of change } \\
\text { opportunities in each period }\end{array}$ \\
\hline \multicolumn{3}{|c|}{ Score tests: extra CES-D effects tested } \\
\hline Incoming friendships & $z_{i} \sum_{j} x_{j i}$ & $\begin{array}{l}\text { Test of main effect of adolescent's number } \\
\text { of received nominations }\end{array}$ \\
\hline Outgoing friendships & $z_{i} \sum_{j} x_{j i}$ & $\begin{array}{l}\text { Test of main effect of adolescent's number } \\
\text { of nominated friends }\end{array}$ \\
\hline $\begin{array}{l}\text { CES-D average friend } \\
\text { similarity } \times \text { reciprocity }\end{array}$ & $x_{i(r)}^{-1} \sum_{j} x_{i j} x_{j i}\left(\operatorname{sim}_{i j}-\overline{\operatorname{sim}}\right)$ & $\begin{array}{l}\text { Test of whether the effect of average friend } \\
\text { CES-D similarity differs among reciprocal } \\
\text { and nonreciprocal friends }\end{array}$ \\
\hline
\end{tabular}

Note: All covariates are centered at the grand mean. CES-D = Center for Epidemiologic Studies Depression Scale. a. $\operatorname{sim}_{i j}=I-\left|v_{i}-v_{j}\right| / \max _{i j}\left|v_{i}-v_{j}\right|$. Note too that $x_{i+}$ is the total number of friends nominated by $i$, and $\overline{\operatorname{sim}}$ is the average similarity.

b. varname $=v$, CES-D score $=z$.

c. $x_{i(r)}^{-1}$ is the inverse of the count of the ego's reciprocated friendships.

turing the influence of friends' CES-D scores, for which the friend influence hypothesis predicts a positive $\beta_{k}^{\text {beh }}$. This parameter is defined as the average of the egos' (i) CES-D similarity to each of their friends $(j$; thus the summation over $j$ and division by the count over $j$ denoted by $x_{i+}^{-1}$ ). Additional covariates $(v)$ are included as main effects and so capture increases or decreases in CES-D score $(z)$. The linear and quadratic shape coefficients express the shape of the distribution and thus contribute to the evaluation function, $f_{i}^{\text {beh }}(x, z, v)$, by indicating movement toward globally optimal values given the current value of $z_{i}{ }^{3}$

\section{Analysis}

The analysis uses the SIENA software (Ripley, Snijders, and Preciado Lopez 2011) to model friendship and depressive symptom changes in the joint combined social network of the schools. Because youth in different schools are unable to select one another as friends, out-ofschool elements in the sociomatrices are fixed. ${ }^{4}$ All respondents were included in the analysis and were allowed to enter the study later or leave early (i.e., those who graduated from high school) using the composition change method of Huisman and Snijders (2003). Missing attributes and CES-D data were treated as noninformative, following the method described by Huisman and Steglich (2008), so that missing values are imputed within the model, but only observed values contribute to the estimated change statistics in the estimation algorithm. Additional parameters that were not included in the analysis are also presented at the bottom of Table 2 . Whether these parameters should be included were assessed using score tests to determine if they improved the model performance against a baseline model including the network structure effects and CES-D influence and selection parameters (Schweinberger 2012). Score tests determining the improvement in the model fit 
Table 3. Descriptive Statistics for the Total, Boy, and Girl Samples

\begin{tabular}{|c|c|c|c|c|c|c|c|c|c|}
\hline \multirow[b]{2}{*}{ Variable } & \multicolumn{5}{|c|}{ Total sample } & \multicolumn{2}{|c|}{ Male } & \multicolumn{2}{|c|}{ Female } \\
\hline & Observations $^{a}$ & M & SD & Minimum & Maximum & M & SD & M & $S D$ \\
\hline \multicolumn{10}{|c|}{ Dependent variable: CES-D score } \\
\hline Wave I in home & 796 & 4.19 & 2.82 & I & 10 & 4.04 & 2.67 & 4.36 & 2.96 \\
\hline Wave 2 in home & 627 & 4.17 & 2.83 & I & 10 & 3.88 & 2.71 & 4.45 & 2.92 \\
\hline Proportion decreased & 625 & 0.37 & & 0 & $\mathrm{I}$ & 0.37 & & 0.36 & \\
\hline $\begin{array}{l}\text { Proportion stayed the } \\
\text { same }\end{array}$ & 625 & 0.27 & & 0 & I & 0.26 & & 0.27 & \\
\hline $\begin{array}{l}\text { Proportion increased } \\
\text { Network characteristics }\end{array}$ & 625 & 0.37 & & 0 & 1 & 0.37 & & 0.36 & \\
\hline $\begin{array}{l}\text { Off-list nomination } \\
\text { count }\end{array}$ & 798 & 2.39 & 2.20 & 0 & 10 & 1.12 & 1.36 & 1.19 & 1.21 \\
\hline $\begin{array}{l}\text { Restricted nominated } \\
\text { sample }\end{array}$ & 798 & 0.40 & & 0 & 1 & 0.41 & & 0.39 & \\
\hline $\begin{array}{r}\text { Alter CES-D } \\
\text { (exclusion) }\end{array}$ & 798 & -0.61 & 5.18 & -25.0 & 20.4 & -0.53 & 3.61 & 0.18 & 4.12 \\
\hline $\begin{array}{l}\text { Ego CES-D } \\
\text { (withdrawal) }\end{array}$ & 796 & -0.50 & 10.90 & -27.2 & 40.2 & -0.19 & 5.88 & -0.07 & 6.91 \\
\hline $\begin{array}{l}\text { Average friend similar- } \\
\text { ity (homophily) }\end{array}$ & 688 & 0.66 & 0.19 & 0 & 1 & 0.68 & 0.22 & 0.63 & 0.22 \\
\hline Received nominations & 798 & 3.28 & 2.93 & 0 & 19 & 1.89 & 1.72 & 1.92 & 1.73 \\
\hline Out nominations & 779 & 3.36 & 2.27 & 0 & 10 & 1.94 & 1.41 & 1.99 & 1.37 \\
\hline Reciprocal ties count & 779 & 1.20 & 1.31 & 0 & 7 & 0.85 & 0.99 & 0.93 & 1.06 \\
\hline Transitive triplets count & 779 & 3.37 & 4.83 & 0 & 29 & 1.16 & 1.70 & 1.36 & 2.22 \\
\hline \multicolumn{10}{|l|}{ Covariates } \\
\hline Female & 798 & 0.50 & & 0 & 1 & & & & \\
\hline Grade & 795 & 9.47 & 1.69 & 7 & 12 & 9.47 & 1.72 & 9.47 & 1.66 \\
\hline White & 798 & 0.97 & & 0 & I & 0.98 & & 0.96 & \\
\hline Parent education & 717 & 2.63 & 1.04 & I & 5 & $2.6 \mathrm{I}$ & 1.03 & 2.66 & 1.04 \\
\hline Single parent & 721 & 0.22 & & 0 & I & 0.22 & & 0.22 & \\
\hline Parent support & 610 & 0.27 & 0.93 & -4.12 & 1.31 & 0.31 & 0.82 & 0.24 & 1.03 \\
\hline Self-esteem & 798 & 0.14 & 0.94 & -3.52 & 1.56 & 0.29 & 0.85 & -0.01 & 1.00 \\
\hline
\end{tabular}

Note: CES-D = Center for Epidemiologic Studies Depression Scale.

a.Observations for CES-D score change between waves I and 2 largely because of high school graduation.

were also used to simplify the model structure with respect to the control variables so that not all ego, alter, and similarity parameters are included for each covariate.

Additionally, the contribution of the different processes to the autocorrelation between the friendship network and CES-D score is decomposed by the simulation method described in Steglich et al. (2010; see also Mercken et al. 2010). The spatial network-CES-D autocorrelation is calculated using Moran's I (Moran 1950) across a special model series disaggregating the contributions of the different mechanisms to this correlation. In this way, depressive symptom similarity is decomposed into the propor- tionate contributions of selection (by type), influence, alternative mechanisms from the other covariates and structural network effects (i.e., controls), and general trend effects indicating state dependencies in friendships and individual distress.

\section{Results}

Descriptive statistics for the total, boy, and girl samples are presented in Table 3. On average, approximately 3.5 in-school and nearly 2.5 additional (unmatched within-school off-list) friends were nominated. Of the youth in the sample over the entire study period who did 
not graduate, drop out, or change schools, CESD scores were consistent for 25 percent, while the rest, evenly split, increased or decreased by at least one decile. Girls had slightly more depressive symptoms than boys, and whereas girls' scores increased slightly, boys' scores decreased. The overall percentages moving up and down, however, were similar. With respect to the focal parameters, the social exclusion and withdrawal counts were widely dispersed and indicated that youth with lower CES-D scores were more likely to be nominated and less likely to nominate others. There were slight gender differences in exclusion, with girls above the mean on CES-D score slightly more likely to be selected as friends. Average friend similarity on depressive symptoms, relevant for the homophilous selection and assimilation hypotheses, was 0.66 , indicating that most friends were relatively similar to one another. The boys were slightly more similar to each other than the girls were (0.68 to 0.63 ).

\section{Dynamics in the Total Sample}

The model series for the full sample is presented in Table 4. We reiterate here that we used score tests to build the model parsimoniously so that not all possible effects were estimated. Coefficients are in logit metrics for both the network change model and depressive symptoms. In the first model, A0, network and distress dimensions evolve independently from each other so that the network dynamics can be considered in isolation from those for CES-D. The out-degree density parameter is large and negative because adolescents were only able to nominate (or only nominated) a few friends out of the total pool, and the large positive reciprocity indicates the tendency for friendships to be reciprocated. That is, the odds of a friendship are 7.6 times $(\exp [2.03])$ larger if the tie is reciprocal, all else equal. The triadic effects, namely, the positive transitive triplets effect and the proscription against distance $=2$ connections, show that friendship changes reflect opportunities available by virtue of existing connections, and thus adolescents become friends with their friends' friends (triadic closure). Moreover, when combined with this finding, the negative three-cycles coefficient implies that there is tendency for some youth to be locally more popular than others (Ripley et al. 2011). ${ }^{5}$

Turning to the control variables in model $\mathrm{A} 0$, those with more off-list nominations report fewer friends in school, as expected. Score tests revealed that off-list nominations were not related to receipt of nominations or homophilous selection (similarity). The positive effect for being in the restricted nomination sample suggests that these youth were more likely to become friends over time, reflecting the unequal probability of being in the restricted nomination sample across schools. Finally, the shape parameters describe the shape of the CES-D as mostly flat and slightly decreasing, reflecting the decile coding and slight decline in depressive symptoms over time.

The remaining models explicitly address the substantive hypotheses. Model A1 removes the triadic network effects and includes the effects of CES-D on friendship dynamics, while the network dynamics enter the CES-D equations through the average friend similarity effect capturing influence. First, this model provides support for both the exclusion and homophilous selection mechanisms. The negative exclusion coefficient $(b=-0.028)$ indicates that youth with more depressive symptoms are less likely to receive friendship nominations, while the positive similarity (homophilous selection) parameter $(b=0.53)$ documents a tendency for friends to have similar CES-D scores such that two adolescents perfectly similar have odds of being friends 1.7 times larger than those who are perfectly dissimilar.

Second, the positive similarity coefficient in the CES-D model $(b=2.4)$ further shows social influence effects: Changes in CES-D scores among friends move toward each other or become more similar. In other words, there is evidence that though more depressed youth are excluded in the network, they tend to find one another, and that over time, their moods adjust to their friends'. Regarding the odds of a decile CES-D score change, a 0.1 increase in similarity is associated with a 30 percent $(\exp [2.4 \times$ $0.1]=1.3$ ) increase in the odds. Finally, the negative private school coefficient indicates greater decreases in depressive symptoms relative to those in public schools.

Model A2 addresses the possible biasing role of network processes by adding the network closure effects. Overall, the results change little from those reported previously, although the homophilous selection coefficient decreases to $0.41(p<.10)$ and is no longer statistically significant at $p<.05$. In fact, the general results pattern continues into model A3 when a subset of the control variables is added. Both the 
Table 4. Parameter Estimates (in Logits) and Standard Errors (in Brackets) for Models of Joint Network and CES-D Score Evolution over Two Waves $(n=798)$

\begin{tabular}{|c|c|c|c|c|c|}
\hline Parameter & Model A0 & Model AI & Model A2 & Model A3 & Model A4 \\
\hline \multicolumn{6}{|l|}{ Network: CES-D } \\
\hline Alter (potential friend; exclusion) & & $\begin{array}{c}-0.028^{* *} \\
{[0.013]}\end{array}$ & $\begin{array}{c}-0.032^{* *} \\
{[0.013]}\end{array}$ & $\begin{array}{c}-0.028 * * \\
{[0.014]}\end{array}$ & $\begin{array}{c}-0.026 * * \\
{[0.013]}\end{array}$ \\
\hline Ego (adolescent; withdrawal) & & $\begin{array}{l}-0.018 \\
{[0.013]}\end{array}$ & $\begin{array}{l}-0.003 \\
{[0.015]}\end{array}$ & $\begin{array}{l}-0.001 \\
{[0.013]}\end{array}$ & $\begin{array}{l}-0.01 \\
{[0.015]}\end{array}$ \\
\hline Similarity (potential friend and adolescent) & & $\begin{array}{l}0.525^{* *} \\
{[0.219]}\end{array}$ & $\begin{array}{c}0.406^{*} \\
{[0.216]}\end{array}$ & $\begin{array}{c}0.47 * * \\
{[0.220]}\end{array}$ & $\begin{array}{c}0.505^{*} \\
{[0.259]}\end{array}$ \\
\hline \multicolumn{6}{|l|}{ Network: structural parameters } \\
\hline Out-degree density & $\begin{array}{c}-2.047^{* *} \\
{[0.085]}\end{array}$ & $\begin{array}{c}-2.486 * * \\
{[0.043]}\end{array}$ & $\begin{array}{c}-2.075^{* *} \\
{[0.108]}\end{array}$ & $\begin{array}{l}-2.726^{* *} \\
{[0.147]}\end{array}$ & $\begin{array}{c}-2.943 * * \\
{[0.152]}\end{array}$ \\
\hline Reciprocity & $\begin{array}{c}2.026 * * \\
{[0.082]}\end{array}$ & $\begin{array}{l}1.977^{* *} \\
{[0.065]}\end{array}$ & $\begin{array}{c}2.018^{* *} \\
{[0.088]}\end{array}$ & $\begin{array}{l}1.721^{* *} \\
{[0.075]}\end{array}$ & $\begin{array}{l}1.722^{* * *} \\
{[0.082]}\end{array}$ \\
\hline Transitive triplets & $\begin{array}{c}0.426 * * \\
{[0.035]}\end{array}$ & & $\begin{array}{c}0.421^{* *} \\
{[0.040]}\end{array}$ & $\begin{array}{c}0.384 * * \\
{[0.038]}\end{array}$ & $\begin{array}{c}0.396 * * \\
{[0.036]}\end{array}$ \\
\hline Three-cycle & $\begin{array}{l}-0.476 * * \\
{[0.063]}\end{array}$ & & $\begin{array}{c}-0.48 * * \\
{[0.074]}\end{array}$ & $\begin{array}{c}-0.48 * * \\
{[0.064]}\end{array}$ & $\begin{array}{l}-0.492^{* *} \\
{[0.067]}\end{array}$ \\
\hline Number distance $=2$ & $\begin{array}{l}-0.333^{* *} \\
{[0.039]}\end{array}$ & & $\begin{array}{l}-0.33 I^{* *} \\
{[0.046]}\end{array}$ & $\begin{array}{l}-0.245^{* *} \\
{[0.035]}\end{array}$ & $\begin{array}{c}-0.226^{* *} \\
{[0.037]}\end{array}$ \\
\hline \multicolumn{6}{|l|}{ Network: control variables } \\
\hline Off-list nominations, alter & $\begin{array}{l}-0.083 * * \\
{[0.013]}\end{array}$ & $\begin{array}{c}-0.08 * * \\
{[0.012]}\end{array}$ & $\begin{array}{c}-0.08 * * \\
{[0.014]}\end{array}$ & $\begin{array}{l}-0.07 I^{* *} \\
{[0.013]}\end{array}$ & $\begin{array}{c}-0.069 * * \\
{[0.013]}\end{array}$ \\
\hline Restricted nominations, same sample & $\begin{array}{l}0.196 * * \\
{[0.043]}\end{array}$ & $\begin{array}{l}0.156^{* *} \\
{[0.043]}\end{array}$ & $\begin{array}{c}0.196^{* *} \\
{[0.044]}\end{array}$ & $\begin{array}{c}0.217 * * \\
{[0.044]}\end{array}$ & $\begin{array}{c}0.231^{* *} \\
{[0.043]}\end{array}$ \\
\hline Same sex & & & & $\begin{array}{c}0.267 * * \\
{[0.043]}\end{array}$ & $\begin{array}{c}0.276 * * \\
{[0.043]}\end{array}$ \\
\hline Same grade & & & & $\begin{array}{c}0.704 * * \\
{[0.045]}\end{array}$ & $\begin{array}{c}0.712^{* *} \\
{[0.049]}\end{array}$ \\
\hline Same race/ethnicity (white/nonwhite) & & & & $\begin{array}{c}0.066 \\
{[0.12 I]}\end{array}$ & $\begin{array}{c}0.217^{*} \\
{[0.125]}\end{array}$ \\
\hline Parent education similarity & & & & $\begin{array}{c}0.300^{* *} \\
{[0.115]}\end{array}$ & $\begin{array}{c}0.305 * * \\
{[0.107]}\end{array}$ \\
\hline Single parent, ego & & & & $\begin{array}{l}-0.105 \\
{[0.068]}\end{array}$ & $\begin{array}{c}-0.095 \\
{[0.066]}\end{array}$ \\
\hline Single parent, same & & & & $\begin{array}{c}0.102 * * \\
{[0.05 \mathrm{I}]}\end{array}$ & $\begin{array}{l}0.111 * * \\
{[0.049]}\end{array}$ \\
\hline Parent support (z), ego & & & & & $\begin{array}{c}0.023 \\
{[0.033]}\end{array}$ \\
\hline Self esteem (z), ego & & & & & $\begin{array}{c}-0.053^{*} \\
{[0.029]}\end{array}$ \\
\hline CES-D: as & & & & & \\
\hline CES-D average friend similarity & & $\begin{array}{c}2.420 * * \\
{[0.882]}\end{array}$ & $\begin{array}{c}2.727 * * \\
{[1.376]}\end{array}$ & $\begin{array}{l}2.592 * * \\
{[0.980]}\end{array}$ & $\begin{array}{c}2.128 * \\
{[1.124]}\end{array}$ \\
\hline Private school & & $\begin{array}{l}-0.074^{* *} \\
{[0.035]}\end{array}$ & $\begin{array}{l}-0.067^{* *} \\
{[0.032]}\end{array}$ & $\begin{array}{l}-0.022 \\
{[0.034]}\end{array}$ & $\begin{array}{l}-0.023 \\
{[0.033]}\end{array}$ \\
\hline Parent education & & & & $\begin{array}{l}-0.061^{* *} \\
{[0.017]}\end{array}$ & $\begin{array}{l}-0.062^{* *} \\
{[0.017]}\end{array}$ \\
\hline Parent support (z) & & & & & $\begin{array}{c}-0.056 * * \\
{[0.021]}\end{array}$ \\
\hline Self-esteem (z) & & & & & $-0.048 * *$ \\
\hline
\end{tabular}


Table 4. (continued)

\begin{tabular}{lccccc} 
Parameter & Model A0 & Model AI & Model A2 & Model A3 & Model A4 \\
\hline & & & & & {$[0.020]$} \\
Behavioral shape parameters & & & & & \\
$\quad$ Linear shape parameter & $-0.034^{* *}$ & -0.012 & -0.009 & -0.012 & -0.015 \\
& {$[0.015]$} & {$[0.018]$} & {$[0.021]$} & {$[0.018]$} & {$[0.018]$} \\
& $-0.006^{*}$ & $0.014^{*}$ & 0.015 & 0.013 & 0.003 \\
Quadratic shape parameter & {$[0.003]$} & {$[0.007]$} & {$[0.012]$} & {$[0.008]$} & {$[0.008]$}
\end{tabular}

Note: CES-D $=$ Center for Epidemiologic Studies Depression Scale.

${ }^{*} p<.10 .{ }^{* *} p<.05$.

homophilous selection and influence parameters are marginally significant $(p<.10)$ in model A4 when the parent support and self-esteem parameters are included. Both parameters remain relatively large, however. Overall, these findings provide evidence of the role of social exclusion and homophilous selection in friendship networks and that friends influence one another's emotional distress.

The remaining parameters in model A4 correspond with general homophilous trends as well: Friends are more likely to be the same sex, be in the same grade, be the same race, and have parents with similar educational backgrounds and marital status. The self-esteem ego coefficient is unexpectedly negative, indicating a social withdrawal effect conditional on the other parameters included in the model. In the behavioral model, parent education, support, and selfesteem are all negatively related to depressive symptoms. Finally, the private school indicator effect is the result of different parent education levels between children attending the different school types. These small school results thus point to the importance of larger social structural factors arranging relationships locally.

To provide a better sense of effect magnitudes, Table 5 presents the estimated networkCES-D autocorrelation along with a percentage decomposition of this autocorrelation into trend effects (i.e., state dependence in friendships and CESD). Contributions of control variables and structural network effects, exclusion, withdrawal, homophilous selection, social influence, and the residual correlation are also included. Approximately 11 percent of the networkCESD autocorrelation is due to general stability or trend effects, while another 17 percent reflects the control variables. Notably, the most salient process is social influence, at 37 percent, while the second most important process is social selection, at 25 percent. Overall, neither the withdrawal or exclusion mechanisms play a very strong role. In summary, these findings suggest that adolescents prefer friends with levels of distress similar to their own but also that their own levels of distress even more strongly react to that of their friends'.

We also explored a number of additional structural effects on CES-D score changes that were not included in the presented models. Adolescent depressive symptoms are unrelated to friend nominations received $\left(\chi^{2}=0.01, d f=1, p\right.$ $=.90)$, suggesting that social exclusion does not increase CES-D scores. The same is true for the number of nominations sent $\left(\chi^{2}=0.1, d f=1, p=\right.$ $.35)$, indicating that social withdrawal is not related to changes in depressive symptoms. Additionally, distress is not exacerbated within reciprocated friendships $\left(\chi^{2}=0.1, d f=1, p=.75\right)$. In other words, the influence of social relationships on depressive symptoms appears to largely operate through the depressive symptoms of those one views as friends, not through other structural network effects (Ueno 2005), reciprocity (Stevens and Prinstein 2005), or a lack of social integration (e.g., Falci and McNeely 2009) in smaller schools.

\section{Dynamics among Boys and Girls}

Next, we turn to the gender-specific analysis assessing whether friendship and CES-D processes differ between boys and girls in gender-specific networks. The effect sizes captured as autocorrelation decompositions are presented in Table 5, and the coefficient estimates and standard errors are reported in Table 6 . The 
Table 5. Percentage Decomposition of the Estimated Network-CES-D Autocorrelation by Mechanism for the Total, Male, and Female Friendship Networks

\begin{tabular}{|c|c|c|c|}
\hline Parameter & Total & Male & Female \\
\hline Trend & II & 16 & 22 \\
\hline Control variables & 17 & 3 & 33 \\
\hline $\begin{array}{l}\text { Alter (potential friend; } \\
\text { exclusion) }\end{array}$ & $\mathrm{I}$ & 1 & 2 \\
\hline $\begin{array}{l}\text { Ego (adolescent; } \\
\text { withdrawal) }\end{array}$ & 0 & 0 & 3 \\
\hline Selection (similarity) & 25 & 27 & 3 \\
\hline $\begin{array}{l}\text { Influence (average friend } \\
\text { similarity) }\end{array}$ & 37 & 47 & 24 \\
\hline Residual autocorrelation & 8 & 7 & 14 \\
\hline $\begin{array}{l}\text { Estimated network } \\
\text { autocorrelation }\end{array}$ & 0.14 & 0.20 & 0.11 \\
\hline
\end{tabular}

Note: CES-D = Center for Epidemiologic Studies Depression Scale.

final column of Table 6 contains $z$ values and significance levels for a comparison of the boygirl coefficient differences. First, as shown in Table 5, the autocorrelation is two times larger among boys than girls, primarily reflecting the combination of influence (47 percent vs. 24 percent) and homophilous selection (27 percent vs. 3 percent). The coefficients capturing these two processes indicate that neither selection nor influence is significant among girls and that the differences relative to boys are marginally significant $(p<.10)$. Overall, then, homophilous selection and social influence in the total network are likely to be driven by the boys. Globally, the findings presented in Table 6 are consistent with the hypothesis that the social dynamics of depressive symptoms are different among girls and boys (Rudolph 2002).

The evidence also points to girls' being more likely to exclude those with higher CES-D scores, contrary to our expectations, and suggesting that processes among girls are more consistent with prior mental health research indicating that depressive symptoms lead to social isolation (e.g., Barnett and Gotlib 1988; Kawachi and Berkman 2001). Boys, however, are more consistent with the adolescent externalizing behavior literature, which suggests that boys are more likely to assimilate to the behavior of others in their friend networks (Brown, Clasen, and Eicher 1986). Additional findings show that reciproc- ity is higher among girls and that there is a marginally stronger tendency toward triadic closure (number distance $=2$ ), so that friend groups are tighter for girls than for boys (Cairns et al. 1998). Friendships among girls are also more likely to be within grade. Although the differences are not statistically significant between boys and girls, the following results may be substantively meaningful because the estimated coefficient is different from zero for one group and not the other: Boys are more likely to be friends with those from similar socioeconomic backgrounds, with similar levels of parent support, and show a social withdrawal effect related to living with a single parent. Girls, on the other hand, are more likely to be friends with those residing in the same family structure.

\section{Depression}

We also assessed whether homophilous social selection is driven by more distressed youth. First, we estimated an alternative homophilous selection parameter (an "ego $\times$ alter" interaction) assessing whether selectivity increases with higher CES-D scores. A further extension (not shown) dichotomized the CESD scores at cutoffs of 16 (17 percent of the sample) and 20 (12 percent) to approximate the dynamics of clinical depression (Roberts et al. 1990). ${ }_{6}$ The results indicated that the social dynamics of depression operate across the distribution of symptoms and are not driven only by those with the most symptoms, though there is a small increase in selectivity for boys with higher CES-D scores. In addition, Fowler and Christakis (2008) reported stronger and more consistent effects using the happiness subscale of the CES-D, but we were not able to replicate those results in this study. In other words, distress, not happiness, appears to be more important among adolescents.

\section{Discussion}

The analysis we present contributes to the sociological literature on adolescent distress in a number of ways. First, the sociological literature itself is not large, and with the exception of only a few studies (Falci and McNeely 2009; Schaefer et al. 2011; Ueno 2005), most samples are small or are not nationally representative (Hogue and Steinberg 1995; Hansell 1985; Prinstein et al. 2005; Stevens and Prinstein 2005). 
Table 6. Parameter Estimates (in Logits) and Standard Errors for Models of Joint Network and CES-D Score Evolution over Two Waves for Boys and Girls Separately

\begin{tabular}{|c|c|c|c|c|c|}
\hline \multirow[b]{2}{*}{ Parameter } & \multicolumn{2}{|c|}{ Boys } & \multicolumn{2}{|c|}{ Girls } & \multirow{2}{*}{$\frac{\text { Compare }}{z}$} \\
\hline & $b$ & SE & $b$ & SE & \\
\hline \multicolumn{6}{|l|}{ Network: CES-D } \\
\hline Alter (potential friend; exclusion) & 0.01 & 0.03 & $-0.07 * *$ & 0.03 & $1.78 *$ \\
\hline Ego (adolescent; withdrawal) & $0.07 *$ & 0.04 & -0.05 & 0.04 & $2.26 * *$ \\
\hline Similarity (potential friend and adolescent) & $2.30 * *$ & 0.96 & 0.43 & 0.57 & $1.67 *$ \\
\hline \multicolumn{6}{|l|}{ Network: structural parameters } \\
\hline Out-degree density & $-3.19 * *$ & 0.40 & $-3.66 * *$ & 0.32 & 0.92 \\
\hline Reciprocity & $1.91 * *$ & 0.17 & $2.56 * *$ & 0.19 & $2.55^{* *}$ \\
\hline Transitive triplets & $0.74 * *$ & 0.10 & $0.76 * *$ & 0.11 & 0.09 \\
\hline Three-cycle & $-0.64 * *$ & 0.16 & $-1.02 * *$ & 0.20 & 1.49 \\
\hline Number distance $=2$ & $-0.17 * *$ & 0.08 & $-0.40 * *$ & 0.10 & $1.87^{*}$ \\
\hline \multicolumn{6}{|l|}{ Network: control variables } \\
\hline Off-list nominations, alter & $-0.09 * *$ & 0.03 & -0.02 & 0.03 & 1.39 \\
\hline Off-list nominations, similarity & -0.15 & 0.31 & $0.96 * *$ & 0.32 & $2.50 * *$ \\
\hline Restricted nominations, same sample & $0.27 * *$ & 0.11 & $0.37 * *$ & 0.10 & 0.74 \\
\hline Same grade & $0.66 * *$ & 0.10 & $0.90 * *$ & 0.10 & $1.65^{*}$ \\
\hline Same race/ethnicity (white/nonwhite) & -0.25 & 0.28 & 0.32 & 0.24 & 1.52 \\
\hline Parent education similarity & $0.70 * *$ & 0.26 & 0.29 & 0.24 & 1.18 \\
\hline Single parent, ego & $-0.27 *$ & 0.16 & -0.06 & 0.16 & 0.93 \\
\hline Single parent, same & 0.01 & 0.11 & $0.24 * *$ & 0.12 & $\mathrm{I} .42$ \\
\hline Parent support $(z)$, similarity & $0.18^{* *}$ & 0.09 & -0.05 & 0.07 & $2.10 * *$ \\
\hline Self-esteem (z), similarity & -0.04 & 0.08 & -0.06 & 0.07 & 0.18 \\
\hline \multicolumn{6}{|l|}{ CES-D: assimilation and covariates } \\
\hline CES-D average friend similarity & $6.7 I^{* *}$ & 2.67 & 0.82 & 1.42 & $1.95^{*}$ \\
\hline Private school & -0.04 & 0.04 & $-0.07 * *$ & 0.03 & 0.78 \\
\hline Parent education & -0.03 & 0.04 & $-0.06 * *$ & 0.03 & 0.66 \\
\hline Parent support (z) & $-0.09 * *$ & 0.03 & $-0.04 *$ & 0.02 & 1.21 \\
\hline Self-esteem (z) & -0.01 & 0.06 & -0.07 & 0.05 & 0.86 \\
\hline \multicolumn{6}{|l|}{ Behavioral shape parameters } \\
\hline Linear shape parameter & 0.02 & 0.03 & 0.03 & 0.02 & 0.44 \\
\hline Quadratic shape parameter & -0.01 & 0.01 & $-0.03 * *$ & 0.01 & 1.11 \\
\hline
\end{tabular}

Note: CES-D = Center for Epidemiologic Studies Depression Scale.

$* p<.10 . * * p<.05$.

This is a long-standing issue in social network research. Although our study, which focuses on adolescents who attended seven small $(n<300)$ Add Health high schools at which longitudinal social network data were collected, is neither large nor nationally representative, it contributes to this growing literature by using a new set of schools and innovative new analytic approaches to further develop an emerging picture of the social dynamics of adolescent distress across different school settings.

Second, we modeled friend influence and selection jointly, controlling each for the other (Steglich, Snijders, and West 2006), which other studies have either failed to do or have had to use ad hoc methods to address (for a review see Steglich et al. 2010). This allows us to contribute both to the growing literature on how social networks influence depressive symptoms and to the emerging discussion about how emotional distress influences friendships as a new wave of scholarship turns the social network into a dependent variable (e.g., Schaefer et al. 2011). Finally, the gender differences we present contribute to the growing body of research documenting important distinctions in social processes among young men and women (Eder, Evans, and Parker 1995). 
Having used complete networks and individual data together, the results suggest, consistent with our first two hypotheses, that the social dynamics of distress involve a complicated joint process with depressive symptoms influencing and being influenced by friendship. That is, friendships form among those with similar distress levels, even while friendships with more distressed youth can be harmful (though those with healthier peers can be beneficial). Moreover, the findings by gender illustrate that friendship processes vary for different groups even within the same network as a result of broader social structural processes. Girl networks are tighter and more cohesive, and distress increases the risk for social exclusion compared with boys. This latter effect is not present for boys, though homophilous selection and social influence are important for them (Hogue and Steinberg 1995).

The fact that the network processes differ between boys and girls points to what qualitative researchers have argued for some time: that social dynamics within school settings are nuanced, variant, and gendered (see Eder et al. 1995). Eder and Hallinan (1978) argued that different socialization and structured interactional emphases between girls and boys lead to different social skill sets emphasizing group processes among boys and a focus on dyadic interactions leading to more intimate and intense relationships among girls (see also Giordano 2003; Rubin et al. 2006). The focus on dyadic relations and self-disclosure leads to greater emotional supportiveness in the maintenance of those relations too (Cyranowski et al. 2000; Kort-Butler 2009), but possibly also burdensome reassurance-seeking behavior that increases the risk that more distressed girls are marginalized in the network.

To the extent that distressed girls are more likely to be marginalized, the tendency toward social exclusion we found among them may reflect the fact that nurturing distressed friends is costly (Kessler and McLeod 1984), even if those costs do not appear to lead to a diffusion of distress through friend influence processes. In fact, friend distress was unrelated to subsequent changes in distress, which contributed to the finding that the network-CES-D autocorrelation was 50 percent smaller for girls than for boys. Consistent with the contention that girls experience more risk factors for depression (NolenHoeksema and Girgus 1994), the network-CESD autocorrelation was also more strongly related to background factors for the female sample. This indicates that adolescent emotional distress among girls in these small school settings responds primarily to other factors and also suggests that despite greater intimacy, girls are better able to protect themselves from the distress of their intimates than are boys.

The results for boys show both homophilous selection and friend influences. Not only do boys select similarly distressed male friends, they also influence one another over time. In general, male relationships tend to be less close and cohesive, and many dimensions of male friendships are guided by their desire to fit into larger peer groups (Prinstein 2007; Rudolph 2002). Boys may worry that sharing their feelings will lead to rejection, so they may find friendships with others with similar distress levels to be more attractive, but at the cost of being negatively influenced by their friends' moods (Johnson 1991; Zeman and Shipman 1997). However, it is not entirely clear why friends matter for boys but not for girls. Boys may not offer one another the same level of support when articulating their feelings, or they may choose similarly distressed friends but feel constrained to suppress their emotions because they receive less support when doing so. One potential result could be poorer, less satisfying interactions that exacerbate distress. There is also some evidence that boys are more likely to use humor in response to stress, which may promote support avoidance among friends (e.g., Rose and Rudolph 2006).

These results raise important questions about the specification of network effects and the role of gender in moderating social processes. As we have shown here, the social mechanisms of distress found in the total network were a mixture of separate processes happening in girl and boy networks. As Schaefer et al. (2011) articulated, interventions must target the appropriate mechanisms (see Thomas et al. 2006) to address adolescent depression while avoiding the cost to social integration. Psychotropic drugs are commonly used for treatment, but they can also increase risks for suicide ideation (Vitiello and Swedo 2004) and may cause additional stigmatization. Moreover, they can exacerbate difficulties integrating because of the "flattened" affect they cause, leading to more avoidance and withdrawal (Schaefer et al. 2011). Psychotherapeutic interventions that focus on reorganizing adolescents' social lives, reducing isolation, and creating supportive rela- 
tionships may thus be more effective (Jacobson et al. 2001), particularly for boys, at least in small-school settings.

There are limitations to our analysis, and the results we present are tentative. First, the weight of the statistical evidence in the final model for the total sample, and the boy-girl differences in the homophilous selection and influence parameters, are marginal $(p<.10$, two-tailed ${ }^{7}$ ). Second, this study covers only a very short one-year period over adolescence. Although studies among adults suggest similar social dynamics of mood across the life course (e.g., Cacioppo et al. 2009; Fowler and Christakis 2008), more studies during adolescence, when the prevalence of depressive symptoms increases, are needed. Third, there are two additional processes that we were not able to incorporate into this study that reflect cross-gender selection processes (e.g., girl $\rightarrow$ boy). Fourth, we have focused on only friendship processes and social relationships are much more varied. Negative relationship networks of bullying and social aggression may be even more critical for understanding the mental health outcomes of many youth (e.g., Faris and Felmlee 2011).

Finally, the schools in this study are small in size, which limits generalizability across settings. The longitudinal network component of Add Health is restricted to a small subset of schools, so we have chosen to focus on smaller, more homogeneous settings. With respect to friend selection, depressive affect may be a relatively subtle signal that is more visible in small schools where everyone knows one another. If so, this would explain why Schaefer et al.'s (2011) selection findings differ from ours. They used a larger set of Add Health schools than we did and did not find evidence of homophilous selection. Indeed, the smaller Add Health school settings are substantially different from the larger settings $(n<300$ for K-12 vs. $n>800$ for 9/10-12). Adolescents are more connected to one another in smaller schools (McNeely, Nonnemaker, and Blum 2002) and more attached to their schools (Crosnoe, Johnson, and Elder 2004), and individuals in the school are more likely to know one another (Leithwood and Jantzi 2009). Network processes can also vary across schools (Mouw and Entwisle 2006), and school size influences the structure of the curriculum (Leithwood and Jantzi 2009), thereby constraining friendship opportunities in larger schools (Kubitschek and Hallinan 1998). For these reasons, we have chosen to limit the heterogeneity in our sample, exchanging a broader set of schools for one more narrowly circumscribed but also more specifically targeting certain types of social environments where the influence of distress on social processes is likely to be the most evident.

This study has a number of strengths as well. For example, we were able to control for a wider range of structural network processes in our models than others directly studying selectivity have been able to (i.e., Crosnoe et al. 2008). Although we did not focus on how structural processes influence depressive symptoms (i.e., Falci and McNeely 2009), our findings suggest that immediate friend influences are more central, at least for boys. In addition, we used full network data that are not biased by the social cognitions of more depressed youth, who tend to view friendships negatively, even when others view them favorably (Rose et al. 2007). Finally, the models we used are designed to deal with the inherent dependencies in network data, so inferences are not undercut by the limited statistical assumptions inherent when traditional statistical approaches are applied to network data (Steglich et al. 2010).

\section{Conclusions}

Although the vast majority of adolescents in the United States attend much larger schools than those studied here, nearly 800,000 students are currently enrolled in K-12 schools (National Center for Education Statistics 2011). This is a small proportion of the total number of students but a nontrivial number of people all the same. Youth in these schools interact in a relatively circumscribed educational environment and so have known one another for years. As the current analysis indicates, distress-based homophilous selection and social influence processes are strongest for boys. Specifically, emotional distress influences the meso-level school friendship network, even while this pattern of friendships, and the distribution of distress within it, is related to individual-level changes in depressive symptoms. Interventions and programs targeting internalizing problems and disorders in small school settings should be aware that processes between boys and girls differ in these ways and, that at least among boys, depressive symptoms have roots that extend beyond individuals and out into the interpersonal social worlds they participate in. 
Acknowledgments - We are thankful to William R. Avison, Christina Falci, Philip Schwadel, Rachelle Winkle-Wagner, David F. Warner, and Tara D. Warner for their helpful comments. An earlier draft of this article was presented at the 2010 American Sociological Association Annual Meeting in Atlanta, August 14 to 17. Special acknowledgment is due Ronald R. Rindfuss and Barbara Entwisle for assistance in the original design. Information on how to obtain the Add Health data files is available on the Add Health Web site: http://www.cpc.unc.edu/addhealth . This research was supported by grant R03AA019479 from the National Institute on Alcohol Abuse and Alcoholism (principal investigator Jacob E. Cheadle) and grant K01 HD 065437 from the National Institute of Child Health and Human Development (principal investigator Bridget Goosby). This research uses data from Add Health, a program project directed by Kathleen Mullan Harris and designed by J. Richard Udry, Peter S. Bearman, and Kathleen Mullan Harris at the University of North Carolina at Chapel Hill and funded by grant P01-HD31921 from the Eunice Kennedy Shriver National Institute of Child Health and Human Development, with cooperative funding from 23 other federal agencies and foundations. No direct support was received from grant P01-HD31921 for this analysis. All opinions and errors are the sole responsibility of the authors and do not necessarily reflect those of either the helpful commentators or the funding agencies sponsoring Add Health.

\section{Notes}

1. Coefficient estimates were consistent when using quintiles.

2. A series of robustness checks comparing results using imputation and other techniques suggested that this decision had a negligible impact on our results.

3. Note that this is quite different from, for example, a quadratic growth curve modeling the nonlinear change in the average across time points.

4. Ripley et al. discussed this and other approaches to analyzing multiple networks. First, there is a full meta-analytic approach requiring estimation on each network separately. This approach is generally considered preferable, because it allows parameters to differ across networks. There were estimation problems due to the small network sizes, model complexity, and limited observations over time, however, so we opted to use this simpler method. In other work with these schools, results have tended to be nearly identical whether network models are grouped as we have done here or the meta-analytic approach is used. A second approach treats schools as different time periods and so allows rate parameters to differ across schools while fixing the coefficients. Inferences with this method were also virtually identical to those reported here.
5. A negative three-cycle effect indicates that ties are not shared equally among members in triads, while the transitive closure effects further indicate that ties asymmetrically connect triad members to one another. The tendency away from 3-cycles and toward closure thus suggests the formation of local hierarchies. This is most apparent in graphical presentations, to which we refer readers to the supporting citation in the text.

6. Similarities are quite high for these variables (0.74 and 0.81 ) because of the number of zeros. Approximately 16 percent of cases were maximally dissimilar (similarity $=0$ ), and close to 50 percent of friend groups were maximally similar (similarity $=1$ ) at the cutoff score of 16 .

7. Relying on $\alpha=.10$ levels in two-tailed tests is equivalent to $\alpha=.05$ levels for directional hypothesis tests, so these results should not be overstated.

\section{References}

Avison, William R. and Donna D. McAlpine. 1992. "Gender Differences in Symptoms of Depression among Adolescents." Journal of Health and Social Behavior 33:77-96.

Barnett, Peter A. and Ian H. Gotlib. 1988. "Psychosocial Functioning and Depression: Distinguishing among Antecedents, Concomitants, and Consequences." Psychological Bulletin 1:97-126.

Bendgren, Mara, Frank Vitaro, Lyse Turgeon, and Francois Poulin. 2002. "Assessing Aggressive and Depressed Children's Social Relations with Classmates and Friends: A Matter of Perspective." Journal of Abnormal Psychology 30:609-24.

Benenson, Joyce F. 1990. "Gender Differences in Social Networks." Journal of Early Adolescence 10: 472-95.

Benenson, Joyce F., Henry Markovits, Melissa Emery Thompson, and Richard W. Wrangham. 2011. "Under Threat of Social Exclusion, Females Exclude More than Males." Psychological Science 22:538-44.

Billy, John O. G., Joseph Lee Rodgers, and J. Richard Udry. 1984. "Adolescent Sexual Behavior and Friendship Choice." Social Forces 62:653-78.

Billy, John O. G. and J. Richard Udry. 1985. "Patterns of Adolescent Friendship and Effects on Sexual Behavior." Social Psychology Quarterly 48:27-41.

Brown, B. Bradford, Donna R. Clasen, and Sue A. Eicher. 1986. "Perceptions of Peer Pressure, Peer Conformity Dispositions, and Self-reported Behavior among Adolescents." Developmental Psychology 22:521-30.

Brown, B. Bradford and James Larson. 2009. "Peer Relationships in Adolescence." Pp. 74-103 in 
Handbook of Adolescent Psychology, 3rd ed., edited by R. Lerner and L. Steinberg. Hoboken, NJ: John Wiley.

Cacioppo, John T., James H. Fowler, and Nicholas A. Cristakis. 2009. "Alone in the Crowd: The Structure and Spread of Loneliness in a Large Social Network." Journal of Personality and Social Psychology 97:977-91.

Cacioppo, James T., Mary E. Hughes, Linda J. Waite, Louise C. Hawkley, and Ronald A. Thisted. 2006. " Loneliness as a Specific Risk Factor for Depressive Symptoms: Cross-sectional and Longitudinal Analysis." Psychology and Aging 21: 140-51.

Cairns, Robert B., Beverly D. Cairns, Holly J. Neckerman, Scott D. Gest, and Jean-Louis Gariepy. 1988. "Social Networks and Aggressive Behavior: Peer Support or Peer Rejection?' Developmental Psychology 24:815-23.

Cairns, Robert, Hongling Xie, and Man-Chi Leung. 1998. "The Popularity of Friendship and the Neglect of Social Networks: Toward a New Balance." New Directions in Child Development 80:25-53.

Carlson, Marcia J. 2006. “Family Structure, Father Involvement, and Adolescent Behavioral Outcomes." Journal of Marriage and Family 68: 137-54.

Cohen, Jere M. 1977. "Sources of Peer Group Homogeneity." Sociology of Education 50:27-241.

Compas, Bruce E., Syndey Ey, and Kathryn E. Grant. 1993. "Taxonomy, Assessment, and Diagnosis of Depression during Adolescence." Psychological Bulletin 114:323-44.

Cornwell, Benjamin. 2003. "The Dynamic Properties of Social Support: Decay, Growth, and Staticity, and Their Effects on Adolescent Depression." Social Forces 81:953-78.

Coyne, James C. 1976a. "Depression and the Response of Others." Journal of Abnormal Psychology 85: 186-93.

Coyne, James C. 1976b. "Toward an Interactional Description of Depression." Psychiatry 39:28-41.

Coyne, James C. and Niall Bolger. 1990. "Doing without Social Support as an Explanatory Concept." Journal of Social Clinical Psychology 9:148-58.

Coyne, James C. and Geraldine Downey. 1991. "Social Factors and Psychopathology: Stress, Social Support, and Coping Processes." Annual Review of Psychology 42:401-25.

Crosnoe, Robert, Kenneth Frank, and Anna Strassmann Mueller. 2008. "Gender, Body Size and Social Relations in American High Schools." Social Forces 86:1189-1216.
Crosnoe, Robert, Monica Kirkpatrick Johnson, and Glen H. Elder. 2004. "School Size and the Interpersonal Side of Education: An Examination of Race/Ethnicity and Organizational Context." Social Science Quarterly 85:1259-74.

Crosnoe, Robert. 2011. Fitting In, Standing Out: Navigating the Social Challenges of High School to Get an Education. New York: Cambridge University Press.

Cyranowski, Jill M., Ellen Frank, Elizabeth Young, and M. Katherine Shear. 2000. "Adolescent Onset of the Gender Differences in Lifetime Rates of Major Depression: A Theoretical Model." Archives of General Psychiatry 57:21-27.

Dishion, Thomas J. and Jessica M. Tipsord. 2011. "Peer Contagion in Child and Adolescent Social and Emotional Development." Annual Review of Psychology 62:189-214.

Dumont, Michelle and Marc A. Provost. 1999. “Resilience in Adolescence: Protective Role of Social Support, Coping Strategies, Self-esteem, and Social Activities on Experience of Stress and Depression." Journal of Youth and Adolescence 28: 343-63.

Eder, Donna, Catherine Colleen Evans, and Stephen Parker. 1995. School Talk: Gender and Adolescent Culture. New Brunswick, NJ: Rutgers University Press.

Eder, Donna and Maureen T. Hallinan. 1978. "Sex Differences in Children's Friendships." American Sociological Review 43:237-50.

Eder, Donna and Stephen Parker. 1987. "The Cultural Production and Reproduction of Gender: The Effect of Extracurricular Activities on Peer-Group Culture." Sociology of Education 60:200-13.

Falci, Christina and Clea McNeely. 2009. "Too Many Friends: Social Integration, Network Cohesion, and Adolescent Depressive Symptoms." Social Forces 87:2031-62.

Faris, Robert and Diane Felmlee. 2011. "Status Struggles: Network Centrality and Gender Segregation in Same- and Cross-gender Aggression." American Sociological Review 76:48-73.

Fine, Gary A. 1980. "The Natural History of Preadolescent Male Friendship Groups." Pp. 293320 in Friendship and Social Relations in Children, edited by H. C. Foot, A. J. Chapman, and J. R. Smith. New York: John Wiley.

Fowler, James H. and Nicholas A. Christakis. 2008. “Dynamic Spread of Happiness in a Large Social Network: Longitudinal Analysis over 20 Years in the Framingham Heart Study." British Medical Journal 337:1-9. 
Friedkin, Noah E. 1998. A Structural Theory of Social Influence. Cambridge, UK: Cambridge University Press.

Gallerani, Catherine M., Judy Garber, and Nina C. Martin. 2010. "The Temporal Relation between Depression and Comorbid Psychopathology in Adolescents at Varied Risk for Depression." Journal of Child Psychology and Psychiatry 51: 242-49.

Giordano, Peggy C. 2003. "Relationships in Adolescence." Annual Review of Sociology 29: 257-81.

Goodman, Elizabeth, Gail B. Slap, and Bin Huang. 2003. "The Public Health Impact of Socioeconomic Status on Adolescent Depression and Obesity." American Journal of Public Health 93:1844-50.

Goodreau, Steven M., James A. Kitts, and Martina Morris. 2009. "Birds of a Feather, or Friend of a Friend? Using Exponential Random Graph Models to Investigate Adolescent Social Networks." Demography 46:103-25.

Hall, Jeffrey A. 2011. "Sex Differences in Friendship Expectations: A Meta-analysis." Journal of Social and Personal Relationships 28:723-47.

Hallinan, Maureen T. and Warren N. Kubitschek. 1990. "The Formation of Intransitive Friendships." Social Forces 69:505-19.

Hansell, Stephen. 1985. "Friendship Networks and Distress in School." Social Forces 63:698-715.

Heider, Fritz. 1958. The Psychology of Interpersonal Relations. New York: John Wiley.

Hogue, Aaron and Laurence Steinberg. 1995. "Homphily of Internalized Distress in Adolescent Peer Groups." Developmental Psychology 31: 697-706.

Hochschild, Arlie Russell. 1979. "Emotion Work, Feeling Rules, and Social Structure." American Journal of Sociology 85:551-75.

Hochschild, Arlie Russell. 1990. “Ideology and Emotion Management: A Perspective and Path for Future Research." Pp. 117-42 in Research Agendas in the Sociology of Emotions, edited by T. D. Kemper. Albany: State University of New York Press.

Huisman, Mark. 2009. "Imputation of Missing Network Data: Some Simple Procedures.” Journal of Social Structure 10:1-29.

Huisman, Mark and Tom A. B. Snijders. 2003. "Statistical Analysis of Longitudinal Network Data with Changing Composition." Sociological Methods \& Research 32:253-87.

Huisman, Mark and Christian Steglich. 2008. "Treatment of Non-response in Longitudinal Network Studies." Social Networks 30:297-308.
Jacobson, Neil S., Christopher R. Martell, and Sona Dimidjian. 2001. “Behavioral Activation Treatment for Depression: Returning to Contextual Roots." Clinical Psychology: Science and Practice 8:255-70.

Johnson, Timothy P. 1991. “Mental Health, Social Relations, and Social Selection: A Longitudinal Analysis." Journal of Health and Social Behavior 32:408-23.

Kalish, Yuval and Garry Robins. 2006. "Psychological Predispositions and Network Structure: The Relationship between Individual Predispositions, Structural Holes and Network Closure." Social Networks 28:56-84.

Kandel, Denise. 1978. "Homophily, Selection, and Socialization in Adolescent Friendships." American Journal of Sociology 84:427-36.

Kawachi, Ichiro and Lisa F. Berkman. 2001. "Social Ties and Mental Health." Journal of Urban Health 78:458-67.

Keiley, Margaret Kraatz, John E. Bates, Kenneth A. Dodge, and Gregory S. Pettit. 2000. "A Crossdomain Growth Analysis: Externalizing and Internalizing Behaviors during 8 Years of Childhood." Journal of Abnormal Child Psychology 28:161-79.

Kessler, Ronald C. and Jane D. McLeod. 1984. "Sex Differences in Vulnerability to Undesirable Life Events." American Sociological Review 49:620-31.

Kort-Butler, Lisa. 2009. "Coping Styles and Sex Differences in Depressive Symptoms and Delinquent Behavior." Journal of Youth and Adolescence 38:122-36.

Kossinets, Gueorgi. 2006. "Effects of Missing Data in Social Networks." Social Networks 28:247-68.

Kubitschek, Warren N. and Maureen T. Hallinan. 1998. "Tracking and Students' Friendships." Social Psychology Quarterly 61:1-15.

Leithwood, Kenneth and Doris Jantzi. 2009. "A Review of Empirical Evidence about School Size Effects: A Policy Perspective." Review of Educational Research 79:464-90.

Link, Bruce G., Francis T. Cullen, Elmer Struening, Patrick E. Shrout, and Bruce P. Dohrewen. 1989. "A Modified Labeling Theory Approach to Mental Disorders: An Empirical Assessment." American Sociological Review 54:400-23.

McNeely, Clea A., James M. Nonnemaker, and Robert W. Blum. 2002. “Promoting School Connectedness: Evidence from the National Longitudinal Study of Adolescent Health." Journal of School Health 72: 138-46.

McPherson, Miller, Lynn Smith-Lovin, and James M. Cook. 2001. “Birds of a Feather: Homophily 
in Social Networks." Annual Review of Sociology 27:415-44.

Mercken, Liesbeth, Tom A. B. Snijders, Christian Steglich, Erkki Vertiainen, and Hein de Vries. 2010. "Dynamics of Adolescent Friendship Networks and Smoking Behavior." Social Networks 32:72-81.

Merikangas, Kathleen. 1984. "Divorce and Assortative Mating among Depressed Patients." American Journal of Psychiatry 141:74-76.

Moody, James. 2001. "Race, School Integration, and Friendship Segregation in America." American Journal of Sociology 107:679-716.

Moran, P. A. P. 1950. “Notes on Continuous Stochastic Phenomena." Biometrika 37:17-23.

Mouw, Ted and Barbara Entwisle. 2006. "Residential Segregation and Interracial Friendship in Schools." American Journal of Sociology 112:394-441.

National Center for Education Statistics. 2011. "Information on Public Schools and School Districts in the United States." Online (September 2011) http://www.nces.ed.gov/ccd/

Nolen-Hoeksema, Susan and Joan S. Girgus. 1994. "The Emergence of Gender Differences in Depression during Adolescence." Psychological Bulletin 115: 424-43.

Pearson, Michael, Christian Steglich, and Tom A. B. Snijders. 2006. "Homophily and Assimilation among Sport-active Adolescent Substance Users." Connections 27:47-63.

Pine, Daniel S., Elizabeth Cohen, Patricia Cohen, and Judith Brook. 1999. "Adolescent Depressive Symptoms as Predictors of Adult Depression: Moodiness or Mood Disorder?" American Journal of Psychiatry 156:133-35.

Prinstein, Mitchell J. 2007. “Moderators of Peer Contagion: A Longitudinal Examination of Depression Socialization between Adolescents and Their Best Friends." Journal of Clinical Child and Adolescent Psychology 36:159-70.

Prinstein, Mitchell J., Jessica L. Borelli, Chariss S. L. Cheah, Valerie A. Simon, and Juli W. Aikins. 2005. "Adolescent Girls' Interpersonal Vulnerability to Depressive Symptoms: A Longitudinal Examination of Reassurance-seeking and Peer Relationships." Journal of Abnormal Psychology 114:676-88.

Radloff, Lenore Sawyer. 1977. "The CES-D Scale." Applied Psychological Measurement 1:385-401.

Rhodes, Jennifer A. and Sarah R. Lowe. 2009. "Mentoring in Adolescence." Pp. 152-89 in Handbook of Adolescent Psychology, 3rd ed., edited by R. M. Lerner and L. Steinberg. Hoboken, NJ: John Wiley.
Ripley, Ruth M., Tom A. B. Snijders, and Paulina Preciado Lopez. 2011. "Manual for RSIENA": http://www.stats.ox.ac.uk/ snijders/siena/ RSiena_Manual.pdf

Roberts, Robert E., Judy A. Andrews, Peter M. Lewinsohn, and Hyman Hops. 1990. "Assessment of Depression in Adolescents Using the Center for Epidemiologic Studies Depression Scale." Journal of Consulting and Clinical Psychology 2:122-28.

Rose, Amanda J. (2002). "Co-rumination in the Friendship of Girls and Boys." Child Development 73:1830-43.

Rose, Amanda J. and Karen D. Rudolph. 2006. “A Review of Sex Differences in Peer Relationship Processes: Potential Trade-Offs for the Emotional and Behavioral Development of Girls and Boys." Psychological Bulletin 132:98-31.

Rose, Amanda J., Wendy Carlson, and Erika M. Waller. 2007. "Prospective Associations of Corumination with Friendship and Emotional Adjustment: Considering the Socioemotional Trade-offs of Co-rumination." Developmental Psychology 43:1019-31.

Rosenblatt, Abram and Jeff Greenberg. 1988. “Depression and Interpersonal Attraction: The Role of Perceived Similarity." Journal of Personality and Social Psychology 60:620-29.

Rubin, Kenneth H., William Bukowski, and Jeffrey Parker. 2006. "Peer Interactions, Relationships, and Groups." In Handbook of Child Psychology: Social, Emotional, and Personality Development, 6 th ed., edited by N. Eisenberg. New York: Wiley.

Rudolph, Karen D. 2002. "Gender Differences in Emotional Responses to Interpersonal Stress during Adolescence." Journal of Adolescent Health 30S: 3-13.

Schaefer, David R., Olga Kornienko, and Andrew M. Fox. 2011. "Misery Does Not Love Company: Network Selection Mechanisms and Depression Homophily." American Sociological Review 76: 764-85.

Schweinberger, Michael. 2012. "Statistical Modelling of Network Panel Data: Goodness of Fit." British Journal of Mathematical and Statistical Psychology 65:263-81.

Shrum, Wesley, Neil H. Cheek Jr., and Sandra M. Hunter. 1988. "Friendship in School: Gender and Racial Homophily." Sociology of Education 61: 227-39.

Snijders, Tom A. B. 1996. "Stochastic Actor-oriented Models for Network Change." Journal of Mathematical Sociology 21:149-72. 
Snijders, Tom A. B. 2001. "The Statistical Evaluation of Social Network Dynamics." Sociological Methodology 31:361-95.

Snijders, Tom A. B., Christian Steglich, and Michael Schweinberger. 2007. "Modeling the Coevolution of Networks and Behavior." Pp. 41-71 in Longitudinal Models in the Behavioral and Related Sciences, edited by K. van Montfort, J. Oud, and A. Satorra. London: Lawrence Erlbaum.

Snijders, Tom A. B., Gerhard G. van de Bunt, and Christian E. G. Steglich. 2010. "Introduction to Stochastic Actor-based Models for Network Dynamics." Social Networks 32:44-60.

Steglich, Christian, Tom A. B. Snijders, and Michael Pearson. 2010. "Dynamic Networks and Behavior: Separating Selection from Influence." Sociological Methodology 40:329-93.

Steglich, Christian, Tom A. B. Snijders, and Patrick West. 2006. "Applying SIENA: An Illustrative Analysis of the Coevolution of Adolescents' Friendship Networks, Taste in Music, and Alcohol Consumption." Methodology 2:48-56.

Stevens, Elizabeth A. and Mitchell J. Prinstein. 2005. "Peer Contagion of Depressogenic Attributional Styles among Adolescents: A Longitudinal Study." Journal of Abnormal Child Psychology 33:25-37.

Thomas, Cindy P., Peter Conrad, Rosemary Casler, and Elizabeth Goodman. 2006. "Trends in the Use of Psychotropic Medications among Adolescents, 1994 to 2001." Psychiatric Services 57:63-9

Ueno, Koji. 2005. "The Effects of Friendship Networks on Adolescent Depressive Symptoms." Social Science Research 34:484-510.

Urberg, Kathryn A., Serdar M. Degirmencioglu, Jerry M. Tolson, and Kathy Halliday-Scher. 1995. "The Structure of Adolescent Peer Networks." Developmental Psychology 31:540-47.

Umberson, Debra, Robert Crosnoe, and Corinne Reczek. 2010. "Social Relationships and Health Behavior across the Life Course." Annual Review of Sociology 36:139-57.
Vitiello, Benedetto and Susan Swedo. 2004. "Antidepressant Medications in Children." New England Journal of Medicine 350:1489-91.

Wade, Terrance J., John Cairney, and David J. Pevalin. 2002. “Emergence of Gender Differences in Depression during Adolescence: National Panel Results from Three Countries." Journal of the American Academy of Child and Adolescent Psychiatry 41:190-98.

Weerman, Frank M. 2011. “Delinquent Peers in Context: A Longitudinal Network Analysis of Selection and Influence Effects." Criminology 49: 253-86.

Wenzlaff, Richard and Mark Prohaska. 1989. "When Misery Prefers Company: Depression Attributions, and Responses to Others' Moods." Journal of Experimental Social Psychology 25: 220-33.

West, Candace and Don H. Zimmerman. 1987. “Doing Gender." Gender \& Society 1:125-51.

Wilson, Coralie and Frank P. Deane. 2010. "Helpnegation and Suicide Ideation: The Role of Depression, Anxiety, and Hopelessness." Journal of Youth and Adolescence 39:291-305.

Witvliet, Miranda, Mara Brendgen, Pol van Lier, Hans Koot, and Frank Vitaro. 2010. “Early Adolescent Depressive Symptoms: Prediction from Clique Isolation, Loneliness, and Perceived Social Acceptance." Journal of Abnormal Child Psychology 38:1045-56.

Youngren, Mary A. and Peter M. Lewinsohn. 1980. "The Functional Relation between Depression and Problematic Interpersonal Behavior." Journal of Abnormal Psychology 89:333-41.

Zeman, Janice and Kimberly Shipman. 1997. "Social-contextual Influences on Expectancies for Managing Anger and Sadness: The Transition from Middle Childhood to Adolescence." Developmental Psychology 33:917-24. 